\title{
Anxiety and Depression Among Adult Patients With Diabetic Foot: Prevalence and Associated Factors
}

\author{
Ali Ahmad a, b, Mousa Abujbara a, b, Hashem Jaddou ${ }^{\mathrm{c}}$, Nidal A. Younes ${ }^{\mathrm{d}}$, \\ Kamel Ajlouni ${ }^{\mathrm{a}, \mathrm{b}}$, e
}

\begin{abstract}
Background: Diabetic foot is a frequent complication of diabetes mellitus with subsequent disturbances in the daily life of the patients. The co-existence of depression and anxiety among diabetic foot patients is a common phenomenon and the role of each of them in perpetuating the other is highlighted in the literature. Our study aimed to determine the prevalence rates of anxiety and depression, and to examine the associated risk factors among diabetic foot patients.
\end{abstract}

Methods: This is a cross-sectional study. A total of 260 diabetic foot patients in the Diabetic Foot Clinic at the National Center for Diabetes, Endocrinology and Genetics (NCDEG), Amman, Jordan, participated in the study. Sociodemographic and health data were gathered through review of medical charts and a structured questionnaire. Depression and anxiety status were also assessed. The Generalized Anxiety Disorder Scale (GAD-7) was used to screen for anxiety and the Patient Health Questionnaire (PHQ-9) was used to screen for depression. A cutoff of $\geq 10$ was used for each scale to identify those who tested positive for anxiety and depression.

Results: Prevalence rate of anxiety was $37.7 \%$ and that of depression was $39.6 \%$. Multiple logistic regression analysis showed that anxiety is positively associated with duration of diabetes of $<10$ years $(\mathrm{P}=$ $0.01)$, with $\geq$ three comorbid diseases $(\mathrm{P}=0.00)$, and $\mathrm{HbA} 1 \mathrm{c}$ level of $>7 \%(\mathrm{P}=0.03)$. Multiple logistic regression analysis also showed that depression is positively associated with patients of $<50$ years of age $(\mathrm{P}=0.03)$, females $(\mathrm{P}=0.01)$, current smokers $(\mathrm{P}=0.01)$, patients with foot ulcer duration $\geq 7$ months $(P=0.00)$, with $\geq$ three comorbid diseases $(\mathrm{P}=0.00)$ than their counterparts.

Conclusions: Anxiety and depression are widely prevalent among diabetic foot patients. Mental health status of those patients gets even

Manuscript submitted January 3, 2018, accepted February 5, 2018

${ }^{a}$ The National Center (Institute) for Diabetes, Endocrinology and Genetic, Amman, Jordan

${ }^{\mathrm{b}}$ The University of Jordan, Amman, Jordan

'The Jordan University of Science and Technology (JUST), Irbid, Jordan ${ }^{\mathrm{d}}$ Department of General Surgery, Faculty of Medicine, The University of Jordan, Amman, Jordan

${ }^{e}$ Corresponding Author: Kamel Ajlouni, National Center (Institute) for Diabetes, Endocrinology and Genetics, The University of Jordan, Amman, Jordan. Email: ajlouni@ju.edu.jo

doi: https://doi.org/10.14740/jocmr3352w worse among those suffering other comorbid diseases, which was a finding that requires special attention in the management of patients with diabetic foot.

Keywords: Anxiety; Depression; Diabetic foot; Jordan

\section{Introduction}

The epidemic curve of diabetes in Jordan is still on the rise jumping from $13.4 \%$ among the age group of 25 years and older in 1998 [1] to $17.1 \%$ in 2008 [2]. Foot problems are common complications of diabetes and are associated with various levels of amputation rate and life-threatening complications. Approximately $15 \%$ of diabetes patients experience a foot ulcer and about $14-24 \%$ of those with foot ulcer require amputation [3].

The co-existence of mental disorders and physical illness and the role of each of them to perpetuate the other are highlighted in the research literature. Diabetic patients are approximately twice more likely to suffer from anxiety and depression than the general population $[4,5]$. Symptoms of generalized anxiety disorder include excessive worry, restlessness, being easily fatigued, trouble concentrating, irritability, sleep disturbance, and muscle tension. If the patients experienced these symptoms most days for more than 6 months, it may cause distress in the patients. Other types of anxiety disorders include separation anxiety, panic disorder, or phobias, among others.

On the other hand, depression is a major risk factor in hospital admissions among diabetic patients [6] and out-patient presentations with diabetes-related complications [7]. Symptoms of major depression include depressed mood, lack of interest in enjoyable activities, increase or decrease in appetite, insomnia or hypersomnia, slowing of movement, lack of energy, feelings of guilt or worthlessness, trouble concentrating, suicidal thoughts or behaviors. If we compare the symptoms of anxiety and depression, there is some overlap. Sleep problems, trouble concentrating, and fatigue are all symptoms of both anxiety and depression. Irritability may also manifest in forms of anxiety or depression (in place of low mood).

There are however, some distinguishing features. People with depression move slowly, and their reactions seem flattened or dulled. People with anxiety tend to be more keyed up, as they struggle to manage their racing thoughts. Another 
distinguishing feature is the presence of fear about the future in people with anxiety. Depressed people who do not have anxiety are less likely to be fraught with worry about future events, as they are often resigned to believing that things will continue to be bad. In other words, they may predict the future based on how they feel in the moment [8].

Diabetic foot patients are more likely to have depression and anxiety than diabetic patients without foot complications $[9,10]$. Diabetic foot ulceration disturbs the daily life of patients including changes in sleep pattern, impaired mobility, and interference with certain aspects of life such as sexuality, feelings of loneliness, powerlessness, anxiety and depression [11]. Furthermore, physically restrictive regimes including the use of offloading measures of the lower limbs could result in increased psychological pressure [12].

Depression in type 2 diabetes is twice more likely to be associated with amputation than non-diabetics [13], and is associated with a two-fold increase of mortality over 5 years among their first diabetic foot ulcer. [14].

Physicians by virtue of their training are experienced in managing diabetes and its complications but very rarely pay attention to the mental health status of their patients. This practice style applies not only to diabetic foot specialists but extends to include primary care physicians. Jordan national strategy for prevention and control of diabetes has been launched since 2005 and training of diabetic foot specialists and primary care physicians were among the main activities of this strategy.

Thus the objectives of this study were two folds: 1) to assess the level of anxiety and depression among diabetic foot patients, 2) to examine the purported risk factors associated with these psychiatric disorders.

\section{Patients and Methods}

A cross-sectional study was carried out during the period from November 1, 2015 to June 1, 2016, on all diabetic foot patients attending the Diabetic Foot Clinic in the National Center for Diabetes, Endocrine, and Genetics (NCDEG) in Amman. The center as the name implies, is a referral center that receives diabetic foot patients from all over the country. On the day of their visit to the diabetic foot clinic, each patient is subjected to routine measures of height and weight, blood pressure, and blood chemistry (fasting blood sugar, HbAlc, lipid profile, renal functions, and liver functions). In this study, all patients aged 18 years and older were invited to participate in the study. Pregnant and lactating women and patients with mental retardation were excluded from the study. All of the 261 eligible patients (except one) had consented and participated in all the study procedures. A structured self-administered questionnaire and the medical files were the sources from which our study data were obtained. The questionnaire is comprised of three parts. The first part gathered sociodemographic data (age, gender, level of education, family monthly income, marital status, and smoking status). The second part gathered data on anxiety disorder using the Arabic-translated pilot-tested version of the Generalized Anxiety Disorder Scale (GAD-7). The Generalized Anxiety Disorder-7 (GAD-7) is a valid and reliable in- strument. It is used for screening and severity measuring of generalized anxiety disorder, according to reported response category of not at all, several days, more than half the days and nearly every day. GAD-7 is a sensitive self-administrated test to assess generalized anxiety disorder. GAD -7 consists of seven items, each of which scored 0 to 3 providing to 0 to 21 severity score scores of 5,10 and 15 represent cut point for mild, moderate, and severe anxiety, respectively. A GAD-7 score $\geq 10$ were considered a cut point for anxiety [15]. The seven items scale was originally developed by Spitzer RL et al [16] and found to have good reliability, 0.89 sensitivity, and 0.82 specificities. A typical example is: "during the last 2 weeks, how often have you been feeling nervous, anxious or on edge". The response on each item ranges from 0 "not at all", 1 "several days", 2 "more than half the days", and 3 "nearly every day". The GAD-7 score range between 0 and 21 and a cut-off point of $\geq 10$ is recommended to identify those who screened positive for anxiety [16]. The Arabic-translated version of GAD-7 was developed and used in previous research [17]. The third part gathered information on the depression status of the participants using the Arabic-translated pilot-tested version of the Patient Health Questionnaire (PHQ-9 [18].The original instrument was developed by Kroenke K et al [19] which is a self-administered version of the PRIME-MD diagnostic instrument for common mental disorders and drawn from the nine DSM-IV criteria that assess depression in primary care. The instrument has been validated for use in clinical practice and found to have adequate convergent and discriminant validity [20]. The internal consistency reliability of the PHQ-9 was excellent, with a Cronbach $\alpha$ of 0.89 , in the primary care setting [21]. For depression assessment, the Patient Health Questionnaire- 9 (PHQ-9) is a valid and reliable instrument. It is used to detect depression. It is used for screening for depression based on the Diagnostic and Statistical Manual of Mental disorder-IV (DSMM-IV) major and minor depressive disorder criteria. It scores each of nine DSM-IV criteria for depression as 0 (not at all), 1(several days), 2, (more than half day) and 3 (nearly every day). The total score is between 0 and 27. These questionnaires provide both diagnosis and continuous severity score. PHQ-9 scores of 5, 10, 15 and 20 and above represent mild, moderate, moderately severe, and severe depression respectively. Major depression is diagnosed if five or more of the nine depressive symptom criteria have been present at least more than half the days in the past 2 weeks and one of the symptoms is depressed mood or anhedonia (inability to feel pleasure). Minor depression is diagnosed if two, three or four depressive symptoms have been present at least more than half the days in the past 2 weeks and one symptom is depressed mood or anhedonia. A PHQ -9 scores $\geq 10$ was considered as depression [22]. A typical example is that "over the past 2 weeks how often have you been bothered by any of the followings (little interest or pleasure in doing things)". Participants were asked to use a 4-point frequency scale $(0=$ not at all, $1=$ some of the days, $2=$ more than half the days, and 3 $=$ nearly every day). The PHQ-9 score range from 0 to 27 . The highest levels of sensitivity and specificity ( $88 \%$ and $88 \%$ ) of the instrument were achieved at a cut-off point of 10 [19]. This cut-off point was used in this study to categorize patients into depressed $(\geq 10)$ and not depressed. 
The medical file was used to gather data on weight, height, retinopathy, nephropathy, coronary artery disease (CAD), hypertension, dyslipidemia, and the most recent $\mathrm{HbA} 1 \mathrm{c}$ level. Comorbidity is defined as the sum of chronic diseases (retinopathy, nephropathy, coronary artery disease, hypertension, dyslipidemia) that co-exist with the diabetic foot ulcer.

Statistical analysis was performed using the Statistical Package for Social Sciences (SPSS) version 20. Chi-square test was used to examine the association between two categorical variables. Multiple logistic regression analyses were performed to examine the net effect of the independent variables on the dependent variables of each of depression and anxiety after controlling for the effect of other variables included in the regression model. The odds ratio was antilogarithm of the regression coefficient of the indicator term that correlated to a certain level of the independent variable. The $95 \%$ confidence interval $(\mathrm{CI})$ was calculated using the standard error of the regression coefficient. A P-value $(\mathrm{P}) \leq 0.05$ was considered statistically significant.

\section{Results}

A total of 260 adult diabetic foot patients were recruited in this study. As indicated in Table 1, the majority of the sample were in age group $>60$ years $(43 \%)$, males $(66 \%)$, married $(81.9 \%)$, less than high school education $(47.3 \%)$, an average family monthly income of $<500$ JD $(67 \%)$, non-smokers $(78.8 \%)$, diabetes duration of $\geq 10$ years $(76.9 \%)$, and foot ulcer duration of $<7$ month $(54.2 \%)$. The majority of the sample have uncontrolled HbAlc $(\geq 7)(80.4 \%)$, were hypertensives $(88.5 \%)$, dyslipidemics $(87.3 \%)$, and have peripheral neuropathy $(88.5 \%)$. More than one-third of the sample $(37.6 \%)$ has CAD, $15.8 \%$ have nephropathy, $22.7 \%$ have retinopathy, and $54 \%$ have three or more comorbidities.

\section{Prevalence of depression}

Out of 260 patients, $103(39.6 \%)$ of them suffer from depression. Univariate analysis indicated that women, patients with $\geq$ 7 months duration of foot ulcer, and patients with three chronic diseases or more had significantly higher rates of depression than their counterparts ( $\mathrm{P}=0.01,0.00,0.00$, respectively); the variables of each of age, education level, marital status, income, smoking status, duration of diabetes, and HbAlc level were not significantly associated with depression (Table 1).

Multiple logistic regression analysis was performed to examine the net effect of the independent variables on depression after controlling for the effect of the other variables included in the regression model. As indicated in Table 2, the variables of age, gender, smoking status, foot ulcer duration, and comorbidity were significantly associated with depression. The variables of educational level, marital status, family income, diabetes duration, and $\mathrm{HbAlc}$ level were not significant to the regression model. The risk of having depression among the age group of $<50$ years was 2.79 times compared to the $>60$ years age group $(\mathrm{P}=0.03,95 \% \mathrm{CI}=1.12-6.96)$. The risk of depression among women is 2.45 times compared to men ( $\mathrm{P}$ $=0.01,95 \% \mathrm{CI}=1.21-4.95)$ and among current smokers is 2.51 times compared to non-smokers $(\mathrm{P}=0.01,95 \% \mathrm{CI}=1.2$ 5.24). The likelihood of patients with foot ulcer duration of $\geq 7$ months and patients is 12.62 times compared to those with $<7$ months duration $(\mathrm{P}=0.00,95 \% \mathrm{CI}=1.48-4.67)$ and patients with $\geq$ three comorbidities is 3.25 times compared to $<$ three comorbidities $(\mathrm{P}=0.00,95 \% \mathrm{CI}=1.82-5.83)$.

\section{Prevalence of anxiety}

Out of 260 patients, 98 (37.7\%) of them suffer from anxiety. Univariate analysis indicated that patients with $\geq 7$ months duration of foot ulcer, duration of diabetes of $\geq 10$ years, HbA1c level of $\geq 7 \%$, and patients with three chronic diseases or more had significantly higher rates of anxiety than their counterparts $(\mathrm{P}=0.01,0.02,0.00$, and 0.00 , respectively); the variables of each of age, gender, education level, marital status, income, smoking status were not significantly associated with depression (Table 3).

Results of multiple logistic regression analysis indicated that the variables of diabetes duration, comorbidity, and HbAlc level were significantly associated with anxiety; the variables of age, gender, education level, marital status, income, smoking status, and foot ulcer duration were not significant to the regression model. The risk of anxiety among patients with diabetes duration of $<10$ years is 2.69 times compared to those with diabetes duration of $\geq 10$ years $(\mathrm{P}=0.01,95 \% \mathrm{CI}=1.24$ - 5.81), 4.82 times among patients with three or more chronic disease compared to those with $<$ three chronic diseases $(\mathrm{P}=$ $0.00,95 \% \mathrm{CI}=2.64-8.81)$, and 2.51 times among patients with $\mathrm{HbAlc}$ level of $>7 \%$ compared to those with $\mathrm{HbAlc}$ level of $\leq 7 \%(\mathrm{P}=0.03,95 \% \mathrm{CI}=1.11-5.65)($ Table 4$)$.

\section{Discussion}

The study data indicate that $39.6 \%$ have depression and this figure is comparable to the $39 \%$ reported by OlegaV [21], higher than the $32.2 \%$ and $34.2 \%$ reported among patients with diabetic foot [23], but higher than the $22 \%$ reported by Bala et al [24]. In their study, Carrington et al [25] had noted that patients with diabetic foot reported more depressive symptoms than patients with diabetes alone. On the other hand, Monami et al [26] reported that higher depression score is positively associated with delayed healing of diabetic foot ulcer. These findings point to the bi-directional relationship between depression and diabetic foot ulcer. In agreement with other studies [24, 27], the $<50$ years of age were at higher risk of having depression than the elderly. This finding is perhaps related to socio-cultural and economic factors. The younger age group is still in the active workforce and the bread winners for their families. And the mere thinking of possible amputation of the foot may create a sense of depression and anxiety. On the other hand, Jordanian culture value the extended family in which the elderly are socially and economically supported by the younger siblings, a state that tends to ameliorate the negative impact of the psycho- 
Table 1. Unadjusted and Adjusted Odds Ratios (OR) and the Level of Significance and 95\% Confidence Interval (Cl) of the Association of Depression With Certain Sociodemographic and Health Variables Among Patients With Diabetic Foot ( $\mathrm{N}=260)$

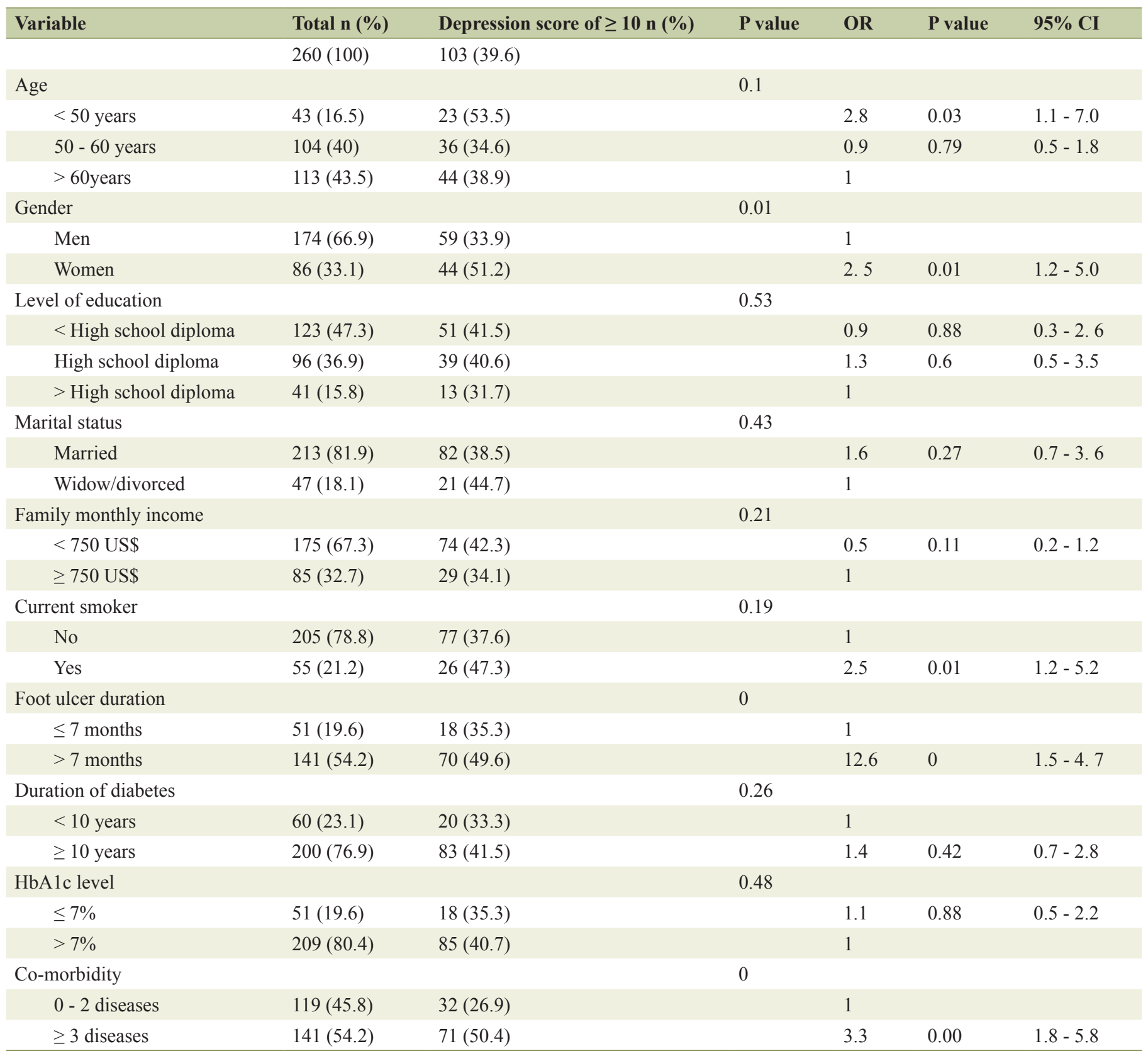

logical disturbances of the elderly with diabetic foot. In accordance with several other studies [28, 29], women in this study are more depressed than men. Medical sociology indicates that women are more sensitive to their body parts and subsequently more utilizers of health services than men. Moreover, women are the caregivers for the family and for themselves when they get sick. These attributes could be the prime movers for feeling endangered by the foot ulcer and its complications. Smoking in our study is positively associated with depression. Several studies [24, 27] have reported the positive association between smoking and depression but the direction of this association is yet to be resolved. In their recent systematic review of the literature, Fluharty $\mathrm{M}$ et al [30] have reviewed 148 longitudinal studies. Nearly half the studies reported that depression/anxiety is a predictor of smoking while more than one-third of the studies reported that smoking at baseline was associated with later depression/anxiety. In the case of diabetic foot ulcer, the vasoconstrictor effect of nicotine plays an important role in the initiation and delayed healing/or non-healing of diabetic foot ulcer, wound infection and dehiscence which in turn initiate or aggravate depression. In agreement with other studies [30, 31], our data show that diabetic foot patients with $\geq 10$ years dura- 
Table 2. : Unadjusted and Adjusted Odds Ratios (OR) and the Level of Significance and 95\% Confidence Interval (CI) of the Association of Anxiety With Certain Sociodemographic and Health Variables Among Patients With Diabetic Foot $(\mathrm{N}=260)$

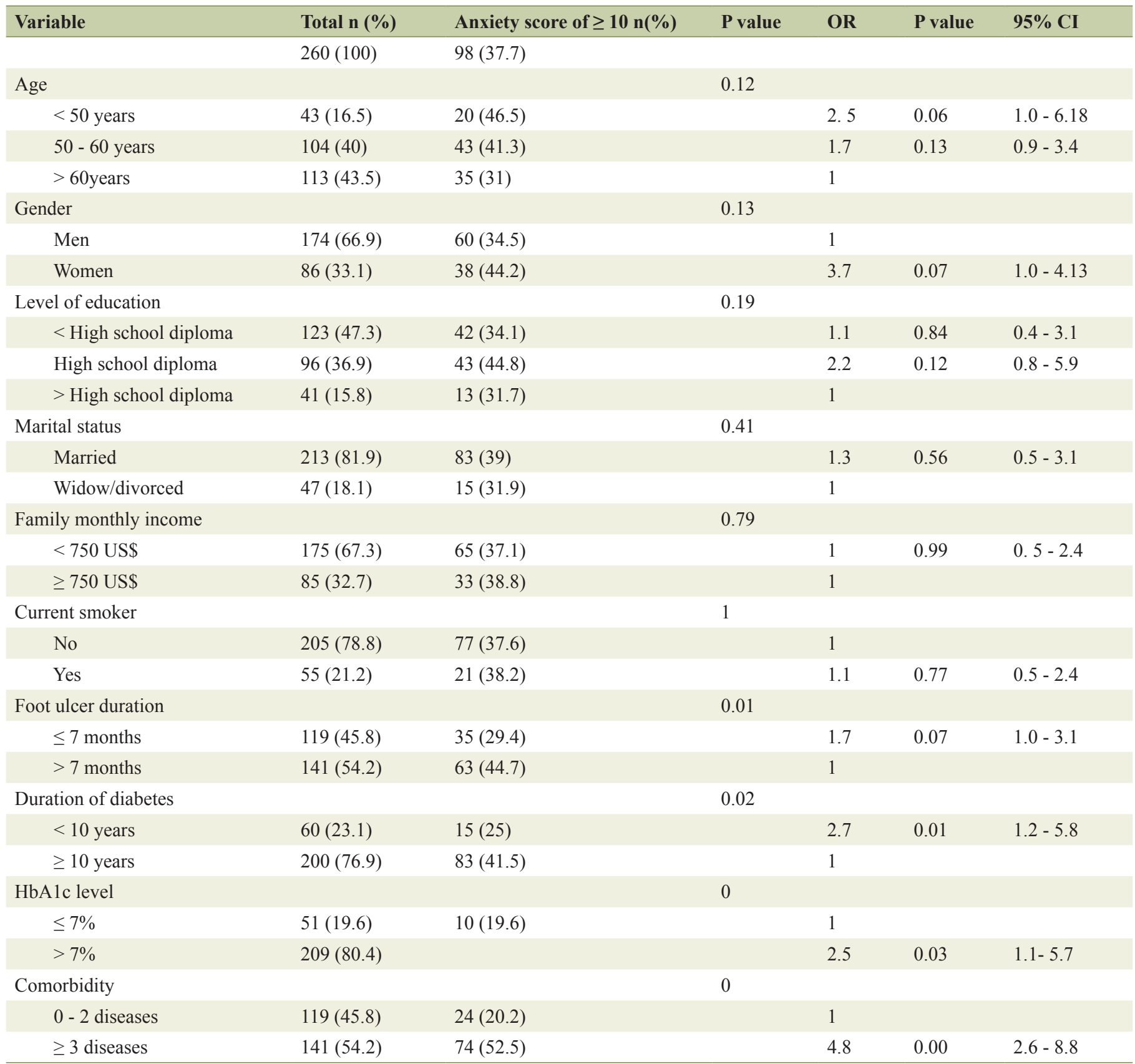

tion of diabetes are more prone to have depression than those with $<10$ years even after controlling for the effect of age and other diabetic complications. Osvaldo et al [31] described the association between duration of diabetes and the risk of depression is "J-shaped". As expected, depression among diabetic patients is directly related to the co-existence of other chronic diseases. This finding is in line with other studies [14, 32-34] that also highlighted the bi-directional association between depression and physical illness.

Our study showed that the prevalence of anxiety was
$37.7 \%$ scored positive for anxiety on GAD-7 scale. This finding is comparable to the 36\% [21] reported among Russian diabetic foot patients but higher than the 14\% [35] and $23 \%$ [36] reported among diabetic patients without foot ulcers. In line with the findings from other studies, our data showed that anxiety is positively associated with younger age [27], female gender [10,27]. The negative relationship between anxiety and duration of diabetes support the findings from another study [37] that attributed this relation to patients' coping experience that improves over the passage of time. Patients' concerns 
Table 3. Adjusted Odds Ratios (OR) and the Level of Significance and $95 \%$ Confidence Interval $(\mathrm{Cl})$ of the Association of Depression With Certain Sociodemographic and Health Variables Among Patients With Diabetic Foot $(N=260)$

\begin{tabular}{|c|c|c|c|}
\hline Variable & OR & P value & $95 \% \mathrm{CI}$ \\
\hline \multicolumn{4}{|l|}{ Age } \\
\hline$<50$ years & 2.8 & 0.03 & $1.1-7.0$ \\
\hline $50-60$ years & 0.9 & 0.79 & $0.5-1.8$ \\
\hline$>60$ years & 1 & & \\
\hline \multicolumn{4}{|l|}{ Gender } \\
\hline Men & 1 & & \\
\hline Women & 2.5 & 0.01 & $1.2-5.0$ \\
\hline \multicolumn{4}{|l|}{ Level of education } \\
\hline$<$ High school diploma & 0.9 & 0.88 & $0.3-2.6$ \\
\hline High school diploma & 1.3 & 0.6 & $0.5-3.5$ \\
\hline$>$ High school diploma & 1 & & \\
\hline \multicolumn{4}{|l|}{ Marital status } \\
\hline Married & 1.6 & 0.27 & $0.7-3.6$ \\
\hline Widow/divorced & 1 & & \\
\hline \multicolumn{4}{|l|}{ Family monthly income } \\
\hline$<750$ US\$ & 0.5 & 0.11 & $0.2-1.2$ \\
\hline$\geq 750$ US\$ & 1 & & \\
\hline \multicolumn{4}{|l|}{ Current smoker } \\
\hline No & 1 & & \\
\hline Yes & 2.5 & 0.01 & $1.2-5.2$ \\
\hline \multicolumn{4}{|l|}{ Foot ulcer duration } \\
\hline$\leq 7$ months & 1 & & \\
\hline$>7$ months & 12.6 & 0 & $1.5-4.7$ \\
\hline \multicolumn{4}{|l|}{ Duration of diabetes } \\
\hline$<10$ years & 1 & & \\
\hline$\geq 10$ years & 1.4 & 0.42 & $0.7-2.8$ \\
\hline \multicolumn{4}{|l|}{ HbA1c level } \\
\hline$\leq 7 \%$ & 1.1 & 0.88 & $0.5-2.2$ \\
\hline$>7 \%$ & 1 & & \\
\hline \multicolumn{4}{|l|}{ Comorbidity } \\
\hline $0-2$ diseases & 1 & & \\
\hline$\geq 3$ diseases & 3.3 & 0.00 & $1.8-5.8$ \\
\hline
\end{tabular}

about treatment procedure, the challenge of diabetes, and the influence of disease complications on physical and psychological functioning improves over time.

Our data showed an inverse relationship between anxiety and foot ulcer duration even after controlling for the effect of other possible confounders. The studies of Ribu et al [34] and Ismail $\mathrm{K}$ et al [14] indicated that patients, who have changes in their feet, will have anxiety (fear for the future), fatigue, limited mobility, social isolation, loneliness, and restricted life activities. This feeling may apply to the first few months of
Table 4. Adjusted Odds Ratios (OR) and The Level of Significance and $95 \%$ Confidence Interval $(\mathrm{Cl})$ of the Association of Anxiety With Certain Sociodemographic and Health Variables Among Patients With Diabetic Foot $(\mathrm{N}=260)$

\begin{tabular}{|c|c|c|c|}
\hline Variable & OR & P-value & $95 \%$ CI \\
\hline \multicolumn{4}{|l|}{ Age } \\
\hline$<50$ years & 2.5 & 0.06 & $1.0-6.18$ \\
\hline $50-60$ years & 1.7 & 0.13 & $0.9-3.4$ \\
\hline$>60$ years & 1 & & \\
\hline \multicolumn{4}{|l|}{ Gender } \\
\hline Men & 1 & & \\
\hline Women & 3.7 & 0.07 & $1.0-4.13$ \\
\hline \multicolumn{4}{|l|}{ Level of education } \\
\hline$<$ High school diploma & 1.1 & 0.84 & $0.4-3.1$ \\
\hline High school diploma & 2.2 & 0.12 & $0.8-5.9$ \\
\hline$>$ High school diploma & 1 & & \\
\hline \multicolumn{4}{|l|}{ Marital status } \\
\hline Married & 1.3 & 0.56 & $0.5-3.1$ \\
\hline Widow/divorced & 1 & & \\
\hline \multicolumn{4}{|l|}{ Family monthly income } \\
\hline$<750$ US\$ & 1 & 0.99 & $0.5-2.4$ \\
\hline$\geq 750$ US\$ & 1 & & \\
\hline \multicolumn{4}{|l|}{ Current smoker } \\
\hline No & 1 & & \\
\hline Yes & 1.1 & 0.77 & $0.5-2.4$ \\
\hline \multicolumn{4}{|l|}{ Foot ulcer duration } \\
\hline$\leq 7$ months & 1.7 & 0.07 & $1.0-3.1$ \\
\hline$>7$ months & 1 & & \\
\hline \multicolumn{4}{|l|}{ Duration of diabetes } \\
\hline$<10$ years & 2.7 & 0.01 & $1.2-5.8$ \\
\hline$\geq 10$ years & 1 & & \\
\hline \multicolumn{4}{|l|}{ HbA1c level } \\
\hline$\leq 7 \%$ & 1 & & \\
\hline$>7 \%$ & 2.5 & 0.03 & $1.1-5.7$ \\
\hline \multicolumn{4}{|l|}{ Comorbidity } \\
\hline $0-2$ diseases & 1 & & \\
\hline$\geq 3$ diseases & 4.8 & 0.00 & $2.6-8.8$ \\
\hline
\end{tabular}

the appearance of the ulcer. But as the time pass by the patient becomes more experienced in coping with the situation and at the same time his level of anxiety drops down to an acceptable level.

There are some limitations of our study. Firstly, the sample may not represent the total population of diabetic foot patients in Jordan. However, Jordan is a small country and the center receives patients referred from all over the country. Secondly, the study design helps measuring the significance and strength of the association but not the direction of the association. 


\section{Conclusions}

Anxiety and depression are widely prevalent among diabetic foot patients. The condition is aggravated by the co-existence of physical illnesses through diverting the attention of healthcare workers from evaluating the psychological status of patients. Treating physicians need to adopt the biopsychosocial model in dealing with diabetic foot patients and be aware of the negative impact of social psychological factors on glycemic control and wound healing.

\section{References}

1. Ajlouni K, Jaddou H, Batieha A. Diabetes and impaired glucose tolerance in Jordan: prevalence and associated risk factors. J Intern Med. 1998;244(4):317-323.

2. Ajlouni K, Khader YS, Batieha A, Ajlouni H, El-Khateeb M. An increase in prevalence of diabetes mellitus in Jordan over 10 years. J Diabetes Complications. 2008;22(5):317-324.

3. Boulton AJM. The diabetic foot. Medicine. 2006;34(3):8790.

4. Ali S, Stone MA, Peters JL, Davies MJ, Khunti K. The prevalence of co-morbid depression in adults with Type 2 diabetes: a systematic review and meta-analysis. Diabet Med. 2006;23(11):1165-1173.

5. Roy T, Lloyd CE. Epidemiology of depression and diabetes: a systematic review. J Affect Disord. 2012;142(Suppl):S8-21.

6. Erkie M, Feleke Y, Desalegne F, Anbessie J, Shibre T. Magnitude, clinical and sociodemographic correlate of depression in diabetic patients, Addis Ababa, Ethiopia. Ethiop Med J. 2013;51(4):249-259.

7. Garrett C, Doherty A. Diabetes and mental health. Clin Med (Lond). 2014;14(6):669-672.

8. Gotlib H, Cane DB. In: Kendall PC, Watson D. (Eds) Anxiety and depression; Distinctive and oterlappingfeatures. Academic Press: San Diego. 1989.

9. Prinz N, Ebner S, Grunerbel A, Henkeludecke U, Hermanns N, Hummel M, Schafer C, et al. Female sex, young age, northern German residence, hypoglycemia and disabling diabetes complications are associated with depressed mood in the WHO-5 questionnaire - A multicenter DPV study among 17,563 adult patients with type 2 diabetes. J Affect Disord. 2017;208:384-391.

10. Chapman Z, Shuttleworth CM, Huber JW. High levels of anxiety and depression in diabetic patients with Charcot foot. J Foot Ankle Res. 2014;7:22.

11. Herber OR, Schnepp W, Rieger MA. A systematic review on the impact of leg ulceration on patients' quality of life. Health Qual Life Outcomes. 2007;5:44.

12. Schram MT, Baan CA, Pouwer F. Depression and quality of life in patients with diabetes: a systematic review from the European depression in diabetes (EDID) research consortium. Curr Diabetes Rev. 2009;5(2):112-119.

13. Williams LH, Miller DR, Fincke G, Lafrance JP, Etzioni R, Maynard C, Raugi GJ, et al. Depression and incident lower limb amputations in veterans with diabetes. J Diabetes Complications. 2011;25(3):175-182.

14. Ismail K, Winkley K, Stahl D, Chalder T, Edmonds M. A cohort study of people with diabetes and their first foot ulcer: the role of depression on mortality. Diabetes Care. 2007;30(6):1473-1479.

15. Al-Khathami AD, Ogbeide DO. Prevalence of mental illness among Saudi adult primary-care patients in Central Saudi Arabia. Saudi Med J. 2002;23(6):721-724.

16. Spitzer RL, Kroenke K, Williams JB, Lowe B. A brief measure for assessing generalized anxiety disorder: the GAD-7. Arch Intern Med. 2006;166(10):1092-1097.

17. Jarab AS, Alqudah SG, Mukattash TL, Shattat G, AlQirim T. Randomized controlled trial of clinical pharmacy management of patients with type 2 diabetes in an outpatient diabetes clinic in Jordan. J Manag Care Pharm. 2012;18(7):516-526.

18. Becker S, Al Zaid K, Al Faris E. Screening for somatization and depression in Saudi Arabia: a validation study of the PHQ in primary care. Int J Psychiatry Med. 2002;32(3):271-283.

19. Kroenke K, Spitzer RL, Williams JB. The PHQ-9: validity of a brief depression severity measure. J Gen Intern Med. 2001;16(9):606-613.

20. Titov N, Dear BF, McMillan D, Anderson T, Zou J, Sunderland M. Psychometric comparison of the PHQ-9 and BDI-II for measuring response during treatment of depression. Cogn Behav Ther. 2011;40(2):126-136.

21. Udovichenko OV, Maximova NV, Amosova MV, Yunilaynen OA, Berseneva EA, Starostina EG. Prevalence and prognostic value of depression and anxiety in patients with diabetic foot ulcers and possibilities of their treatment. Curr Diabetes Rev. 2017;13(1):97-106.

22. Spitzer RL, Kroenke K, Williams JB. Validation and utility of a self-report version of PRIME-MD: the PHQ primary care study. Primary Care Evaluation of Mental Disorders. Patient Health Questionnaire. JAMA. 1999;282(18):1737-1744.

23. Winkley K, Sallis H, Kariyawasam D, Leelarathna LH, Chalder T, Edmonds ME, Stahl D, et al. Five-year followup of a cohort of people with their first diabetic foot ulcer: the persistent effect of depression on mortality. Diabetologia. 2012;55(2):303-310.

24. Bala Neeru, Kaur Gagandeep, Attri Joginder Pal, et al. Psychosocial, psychiatric, and clinical implications of diabetic foot ulceration: A prospective analysis. Journal of Social Health and Diabetes. 2015;3(2):89-94.

25. Carrington AL, Mawdsley SK, Morley M, Kincey J, Boulton AJ. Psychological status of diabetic people with or without lower limb disability. Diabetes Res Clin Pract. 1996;32(1-2):19-25.

26. Monami M, Longo R, Desideri CM, Masotti G, Marchionni N, Mannucci E. The diabetic person beyond a foot ulcer: healing, recurrence, and depressive symptoms. J Am Podiatr Med Assoc. 2008;98(2):130-136.

27. Iversen MM, Midthjell K, Tell GS, Moum T, Ostbye T, Nortvedt MW, Uhlving S, et al. The association between history of diabetic foot ulcer, perceived health and psychological distress: the Nord-Trondelag Health Study. 
BMC Endocr Disord. 2009;9:18.

28. Williams LH, Rutter CM, Katon WJ, Reiber GE, Ciechanowski P, Heckbert SR, Lin EH, et al. Depression and incident diabetic foot ulcers: a prospective cohort study. Am J Med. 2010;123(8):748-754 e743.

29. Salome GM, Blanes L, Ferreira LM. Assessment of depressive symptoms in people with diabetes mellitus and foot ulcers. Rev Col Bras Cir. 2011;38(5):327-333.

30. Fluharty M, Taylor AE, Grabski M, Munafo MR. The association of cigarette smoking with depression and anxiety: a systematic review. Nicotine Tob Res. 2017;19(1):313.

31. Almeida OP, McCaul K, Hankey GJ, Yeap BB, Golledge J, Norman PE, Flicker L. Duration of diabetes and its association with depression in later life: The Health In Men Study (HIMS). Maturitas. 2016;86:3-9.

32. Abdulbari Bener, Abdulla OAA Al-Hamaq, Elnour E Dafeeah. High prevalence of depression, anxiety and stress symptoms among diabetes mellitus patients. The Open Psychiatry Journal. 2011;5:5-12.
33. Brunner EJ, Shipley MJ, Britton AR, Stansfeld SA, Heuschmann PU, Rudd AG, Wolfe CD, et al. Depressive disorder, coronary heart disease, and stroke: dose-response and reverse causation effects in the Whitehall II cohort study. Eur J Prev Cardiol. 2014;21(3):340-346.

34. Ribu L, Wahl A. Living with diabetic foot ulcers: a life of fear, restrictions, and pain. Ostomy Wound Manage. 2004;50(2):57-67.

35. Grigsby AB, Anderson RJ, Freedland KE, Clouse RE, Lustman PJ. Prevalence of anxiety in adults with diabetes: a systematic review. J Psychosom Res. 2002;53(6):10531060.

36. Maia AC, Braga Ade A, Brouwers A, Nardi AE, Oliveira e Silva AC. Prevalence of psychiatric disorders in patients with diabetes types 1 and 2 . Compr Psychiatry. 2012;53(8):1169-1173.

37. Katon W, Lin EH, Kroenke K. The association of depression and anxiety with medical symptom burden in patients with chronic medical illness. Gen Hosp Psychiatry. 2007;29(2):147-155. 